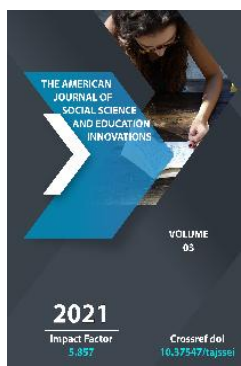

\title{
Developing Students' Critical Thinking In The Process Of Teaching Mathematics In The Primary Grades
}

Feruza Zoxidonovna Khusanova

Lecturer, Of The Department Of Exact And Natural Sciences In Primary Education, Namangan State University, Uzbekistan

Journal Website:

http://theamericanjour

nals.com/index.php/taj

ssei

Copyright: Original content from this work may be used under the terms of the creative commons attributes 4.0 licence.

\section{ABSTRACT}

This article demonstrates the identification of methodological techniques and conditions that help students develop critical thinking in the teaching of combinatorics in the primary grades.

\section{KEYWORDS}

Combinatorics, "combinatorial problem" system of combinatorial problems, system of combinatorial problems combinatorial-critical thinking,

\section{INTRODUCTION}

In our country, mathematics has been identified as one of the priorities for the development of science in 2020 as a task to achieve efficiency in the teaching of mathematics. A number of systematic measures aimed at bringing mathematics science and education to a new level of quality were identified by the Resolution of the 
President of the Republic of Uzbekistan No. PP-4708 of 07.05 .2020 "On measures to improve the quality of education and research in mathematics."

In this regard, teaching methods are becoming more popular, increase learning motivation, increase interest in science, help to teach students basic techniques and skills in traditional and innovative ways with maximum efficiency. There are a variety of pedagogical technologies available today that deserve the attention of teachers.

At the same time, a number of unresolved issues in the field highlight the need to take measures to improve the quality of education and research efficiency in mathematics. Including:

First, the continuity between the learning stages of mathematics education is not fully ensured;

Secondly, mathematics textbooks in secondary schools contain complex issues that make it difficult for students to master the subject depending on their age and are not coordinated with topics taught in other subjects;

Thirdly, despite the fact that most of our talented young people, who are interested in mathematics and are winners of international Olympiads, are from the regions, the necessary conditions for their further development in the field of higher education and science have not been created;

Fourth, the relevance of research in mathematics to practice and production remains weak;
Fifth, the relations of scientists in the field with foreign scientific and educational institutions are not enough to bring national mathematics to the world stage, to increase its prestige in the international community.

Further improvement of the system of teaching mathematics at all levels of education, support of effective work of teachers, expansion of research scope and practical significance, strengthening ties with the international community, as well as the Action Strategy for the five priority areas of development of the Republic of Uzbekistan in 2017-2021 The tasks set out in the State Program for the Year of Science, Enlightenment and Digital Economy have identified priorities for improving the quality of mathematics education, research development and implementation of scientific developments.

At the current stage of development of society, when referendums, credit and insurance policies, various bank payments, etc. are rapidly entering our lives, the inclusion of probabilistic and statistical materials in the school mathematics course becomes clearly relevant.

\section{MATERIALS AND METHODS}

This research topic is relevant for our children because modern school students are more advanced and need not only computational tasks, but also tasks that require the participation of logical thinking in solving them, as well as tasks that are closest to reallife situations. Combinatorics and probability problems are such problems. This article defines the level of logical thinking of 10-13 year old school students. And identifying teaching methods to solve such problems 
allows you to choose the most appropriate method for teaching in school.

A system of combinatorial problems is a set of types and methods of solving combinatorial problems, as well as a certain order of their implementation as a means of mastering the program content of the elementary course of mathematics.

Based on the defined essence of the concept of "system of combinatorial problems", the structural elements of the system of combinatorial problems are revealed. Interrelated subsystems are distinguished: types of combinatorial problems, methods of solving combinatorial problems, stages of implementation of the types and methods of solving combinatorial problems.

The first subsystem includes three types of tasks: switching tasks, placement tasks, and combination tasks.

Second subsystem (combinatorial problem solving methods)

The third subsystem (stages of implementation of types and methods of solving combinatorial problems) consists of preparatory and main stages. The interdependence of the first and second subsystems is as follows: the methods for solving all types of combinatorial problems are the same. The implementation of the interaction is carried out first using the preparatory phase, followed by the solution of combinatorial problems in all types and in different ways (basic phase).

The established system of combinatorial problems, developed on the basis of the methodological concept of the development of teaching mathematics (author N.B. Istomin), became the theoretical basis for the development of a methodology for teaching young students to solve combinatorial problems.

The means of implementing the developed methodology are: the logic of building an elementary course aimed at the formation of methods of mental activity in mathematics: analysis, synthesis, comparison, similarity, classification, generalization; new methodological approaches to the development of theoretical concepts and general methods of action by students; teaching method to solve the word problem aimed at the formation of generalized skills: reading skills, mastering the specific meaning of arithmetic operations, gaining experience in the interconnection of verbal and schematic models of the subject, acquaintance with the scheme, modeling method of acquaintance with the scheme.

The teaching methodology developed for solving combinatorial problems in the conditions of formative experiment was tested.

\section{RESULT AND DISCUSSION}

The results of the comparative-identifying experiment confirmed the hypothesis that if a system of combinatorial problems was developed on the basis of a single methodological concept aimed at developing students, they would learn the main questions in the process of solving them. Judging by the content of the program, it improves the quality of mathematical knowledge of small school students and shapes their ability to solve combinatorial problems. 
"Combinatorics", “combinatorial problem" are defined as starting positions, and on their basis important features of the concept of "system of combinatorial problems" are formed.

Critical thinking technology allows:

Strengthening students' thinking,

To emphasize the main thing, to analyze the situation,

\section{Encourage creativity,}

Show creativity,

Conduct research and draw conclusions.

The need for the use of this technology is determined by the fact that it relates to the evolving education, the modern approach to education, the prospects for cultivating the moral foundations of the personality of schoolchildren.

Elements of critical thinking technology have been used for a long time, but in general, interest in this teaching methodology is only now increasing due to the modernization of the education system and the changing personality of students and teachers.

In turn, the teaching methodology for solving combinatorial problems and the formation of the initial idea of probability in grades 1-4 of primary school.

Although much attention is paid to the formation of the intellectual activity of the student, it should be noted that there is a very low assimilation of combinatorial-critical ways of thinking, both in school and in the social environment.

Therefore, one of the most important tasks of education remains the task of developing students' thinking, one of the main components of which is combinatorial-critical thinking.

By combinatorial-critical thinking we mean the process of production, as a result of which the necessary knowledge, methods and techniques are selected, which are aimed at finding different options, both to solve specific problems and general patterns through model-mind. Meditate

The main development goals of critical thinking technology include:

Development of memory, attention, perseverance;

Develop the ability to highlight the main thing;

The growing influence of development on the formation of personal qualities of the audience;

Formation of skills of comparison, generalization, management, evaluation, analysis, inference;

Development of cognitive abilities, creativity, creativity of personal qualities;

Organization of communication skills (live, virtual, interactive, group, etc.);

Independence, diligence, development of unique abilities; 
Development of logical thinking;

To form an aesthetic image of the surrounding reality;

Initiative, development of cognitive interest;

Teaching search techniques;

Development of mental activity;

Development of practical direction of the studied material;

Development of integrative relations with other disciplines;

Analysis of interdisciplinary relations;

Reliance on moral values;

Growth in developing skills;

Development of lateral thinking;

Use of personal and subjective experience;

Inclusion of a state of "success" in the learning process;

Developing individual characteristics of students.

The following can be added to the development goals when conducting mathematics lessons with elements of critical thinking technology:

Introduction of elements of advanced education;
Develop skills to apply mathematical knowledge in solving practical problems;

Solving more complex problems;

Solve the problem in different ways;

Development of mathematical thinking through active teaching methods;

Development of computing skills, worldview of schoolchildren;

Formation of information culture, mastering the skills of information analysis and search;

- Development of mathematical intuition, logical thinking, application of knowledge in non-standard situations, analytical skills;

- To strengthen the love for mathematics,

- Development of students' communicative competencies (communication culture, ability to work in groups),

Critical thinking, i.e. creative, helps a person to set their own priorities in personal and professional life, includes individual responsibility for the choices made, forms the ability to analyze and draw independent conclusions, predicts and responds to the results of decisions. allows them to develop a culture of communication in joint activities.

\section{CONCLUSION}

It is difficult to motivate the modern student to cognitive activity, to find a way to the goal in the field of information and communication. This is because children often face serious difficulties in comprehending teaching material on all school topics. This is because thinking, including critical thinking, is not 
sufficiently developed. This is very important for a person living in a new century in the modern world with a new kind of knowledge culture.

However, tasks of a combinatorial nature are still classified as increasingly difficult tasks, which are not related to mastering the main issues of the course and do not correspond to the logic of composing its content. In this regard, combinatorial tasks are introduced episodically, unsystematically into the learning process, which significantly reduces their developmental and didactic potential.

\section{REFERENCES}

1. Mirziyoev Sh.M. Together we will build a free and prosperous, democratic state of Uzbekistan. Tashkent, "Uzbekistan", 2016, 56 pages.

2. Action Strategy for the five priority areas of development of the Republic of Uzbekistan for 2017-2021. Decree of the President of the Republic of Uzbekistan dated February 7, 2017 No. PF-4947.

3. Istomina N. B. Mathematics course in elementary school. // Nachalnaya shkola, 1995, №8. S. 49

4. Istomina N. B. Mathematics. Uchebnik dlya vtorogo klassa chetyrexletney nachalnoy shkoly.-Smolensk, 2002.-175p.

5. Istomina N. B. Mathematics. Textbook for the third grade four-year school.Smolensk, 2002.-175p.

6. Istomina N. B. Mathematics. Textbook for the fourth grade four-year primary school.-Smolensk, 2002.-239p.

7. Istomina N. B. Methods of teaching mathematics in primary school.- $M$ : Akademiya, 1999.-288p.

8. Istomina N. B. Metodicheskaya sistema razvivayushchego obucheniya matematike $\mathrm{v}$ nachalnoy shkole. Autoref dr. ped. nauk.M., 1995.-42p.

9. Vilenkin N.Ya., Vilenkin A.N., Vilenkin P.A. Combinatorics. - M: Fima, 2015;

10. Gmurman V.E. Theory of probabilities and mathematical statistics. - M .: Vysshaya shkola, 2006;

11. Abdullayev K. A. Using technologies of subjects'integration in teaching uzbek classic literature //Theoretical \& Applied Science. - 2019. - №. 12. - C. 278-280.

12. Abdullaev K. A. Using historical, scientific and artistic works in learning the personality of alishernavoi //Scientific Bulletin of Namangan State University. 2020. - T. 2. - №. 6. - C. 231-235.

13. Sulaymonov M. Y. Studying the creativity of hafiz khorezmi based on the biographical method //Scientific Bulletin of Namangan State University. - 2019. - T. 1. - №. 4. - C. 190-196.

14. Shermatova M. R. Work On Teaching Classical Literature To Primary School Students //The American Journal of Social Science and Education Innovations. - 2021. - T. 3. - №. 04. - C. 600-605. 